\title{
New trends in regulation of agriculture
}

\author{
Sergey Zyryanov ${ }^{1 *}$, Anastasia Kalmykova ${ }^{1}$, Tatyana Levonenkova $^{1}$, Ekaterina Kozlova ${ }^{1}$, \\ Olyesya Starodubova ${ }^{1}$ \\ ${ }^{1}$ The Institute of Legislation and Comparative Law under the Government of the Russian Federation; \\ Plekhanov Russian University of Economics, 34, B. Cheremushkinskaya st., 117218, Moscow, Russia
}

\begin{abstract}
Regulatory state agencies propose new solutions on regulating relationship in agriculture. Countries with developed agriculture have various national public institutions with a wide range of functions. They develop public policies, set standards, issue licenses and other permissions, do inspections, protect rights of agricultural products consumers, provide support to producers, and etc. Bodies regulating relationship in agriculture act in accordance with the general regulatory trends. Their activity is influenced by modernization and reformation processes, such as deregulation in various forms, transition from a command and control model of regulation to new models providing incentives for producers to voluntarily compliance, risk-based approach introduction, etc. Regulatory tools are often not effective enough for a number of reasons. This work consists of three parts, it evaluates the current state of agriculture in specific actual areas. The first section investigates general trends in the development of regulatory theory and practice. The second section deals with the problems of protecting farmers from unfair trade practices of suppliers and retail chains. The third section presents the results of the analysis of competing provisions on environmental protection and food safety. In conclusion, the authors give a system of new ways of regulation which can replace traditional ways of deterrence.
\end{abstract}

\section{Introduction}

"If people follow the laws for fear of punishment, they will try to avoid punishment and will not feel shame" (Confucius). In modern rapidly changing world, traditional forms and models of regulating the manufacture, providing services and job are not efficient and effective enough. Regulators face new challenges: the demands of society and the demands of politicians reacting them change regularly, new production techniques are introduced, which in turn cause new risks, and costs are being redistributed. The external environment is changing, that is especially important for agriculture, deeply integrated into the world economy. The life standard growth causes the growth of requirements for the quality and safety of products, the consumption structure changes; social movements of environmentalists, consumers, and trade unions become more active. Regulators are often forced to act in conditions of a shortage of reliable information, scientific data on the safety of genetically modified products, used chemical and biological substances, and active

${ }^{*}$ Corresponding author: zyryanov.s@gmail.com 
additives. Agricultural production is a vital strategic sector of the economy both for each individual household, for each state, and for the global economy. Crises and problems sometimes are connected with quite significant risks.

At the same time, it is not always possible to meet needs of producers and consumers with market regulatory tools.

Therefore, the use of state regulators in this sphere of human activity is quite understandable. First, this industry covers a large number of different industries - from fertilizers to finished food products. In agriculture, hazardous chemical and biological substances, technical devices are used, hazardous waste, greenhouse gases are produced [1].

Agriculture is considered to be one of the main water pollutants [2]. In agriculture, as in the other sectors of the economy, threats of economic concentration, unfair competition are inter alia due to unfair trade practices (UTPs). Agricultural production can be a source of danger to the environment, human health, well-being of farmers and consumers, and public good in whole. From time to time consumers become victims of infectious diseases, such as salmonellosis or E-Coli, that indicates the inability of regulators to take measures for preventing such cases in advance. Regulators continue to operate ex post.

In these conditions, demand for effective risk-based regulation, smart regulation providing predictive, anticipatory impact on future threats increases. One of the key indicators of the regulation success is the growth of public welfare, rather than redistribution of goods between producers, consumers, third parties and the budget. In this connection, the role of the regulator's mission increase, as well as the role of setting goals that can be measured.

\section{General trends of modernization in regulation}

Agricultural production is one of the types of economic activity that is the subject to state regulation on the equal basis with other sectors of the economy. Therefore, general trends of changes in the regulatory policy are also evident in this industry. First of all, it should be noted that in the regulation of relationship in agriculture, the command and control model of regulation based on the establishment of mandatory requirements, the issuance of permissions, control and law enforcement against violators traditionally prevailed. This model is rather flexible and variable depending on objective and subjective circumstances [3]. Empirical and intersectoral research (involving economists, sociologists, criminologists), the activity of which has been increasing since the 1980s (Matthew Adler, Ian Ayris, John Brathwaite, Stephen Breyer, Cary Coglianese, Antony Ogus, John Scholz, etc.), clearly indicate the need to revise principles in the regulation, the development and the implementation of new structures, as well as in the involvement of regulated entities themselves, third parties, and local communities in the regulatory processes.

The traditional command and control model of regulation is based on the assumption that regulated entities comply with mandatory requirements only under the threat of punishment and when the costs of punishment exceed the benefits that could be derived from non-compliance, and when the probability of punishment is high enough. It is based on the philosophical ideas of Jeremy Bentham according to which compliance with the law depends on the pain of punishment. The detterence theory is attractive because of its easy implementation, but for its efficiency it is necessary to comply with some conditions describing the ideal model of society: people are all the same, companies are focused only on making profits, laws are simple and clear, people know laws, punishment is the main incentive to comply with the laws, law enforcement agencies are effective and have unlimited resources. In reality, all the people are different. Their behaviour is not deterministic, different people and even the same person in different situations react to the same external stimulus in different ways, and it is impossible to predict anybody's reaction. 
Even simple application to this problem of the prisoner's dilemma shows that people focused on long-term relationships prefer legitimate behaviour even if they can get big and fast money with risky adventures. Empirical studies show that the size of fines has little effect on compliance, trust in government, and cooperation is more effectively than the fear of punishment. Also it is important that deterrence strategies do not contribute to the growth of the public good, but only lead to the redistribution of what is available.

In addition, the major catastrophes occurred in recent decades in the financial, social, and environmental spheres show that regulators must not only restrain illegal behaviour, but also predict, prevent such events, and control risks. Cary Coglianese compares regulators with parents [4].

When it is necessary to hyperregulate the command and control model, due to its inefficiency, regulatory "cat-and - mouse" games begin, regulated persons search for loopholes in the rules, and regulators purposefully detect violations and punish for them. And no one cares about regulatory goals. At the same time, the business community forms a peculiar legal culture of resistance to regulation (Bardach and Kagan, 1982). In addition, punishment is expensive for the regulator, persuasion is cheaper and has a long-term effect.

Among other things, the regulator must foresee consequences of its actions (inaction) and decisions. These actions may affect the rights and interests of not only regulated entities, but also local communities, consumers, and suppliers. Trade unions, manufacturers' associations, professional communities, consumer protection societies, residents of certain districts, media and politicians can join the fight on the side of the regulator or against it.

Strategies based on the cooperation of regulators with regulated persons, giving the latter greater freedom of action are considered to be the most promising. This is due to the transition to performance standards, establishing outputs and allowing regulated persons to find cost-effective and efficient means for meeting these requirements. But for the efficiency of such strategies, the regulator must have, in the apt phrase of Ian Ayres and John Brathwaite the Benign Big Gun (figure 1), it means, the regulator must have at its disposal a pyramid of sanctions and apply the most severe penalties to the disobedient, but sometimes turn a blind eye to minor violations of persons conscientiously trying to ensure compliance. This does not mean that the regulator can arbitrarily apply maximum measures of influence. The Big Gun should remain in the background in constant readiness, while the regulator should act according to the principle of minimum sufficiency (saving legal funds) and strive to achieve the goals of regulation without coercion at all.

In addition to the pyramid of sanctions, the regulator should have at its disposal a pyramid of strategies and as a standard the regulator should offer to regulated persons strategies with minimal interference, such as self-regulation permanently monitoring regulated persons fundamentally unwilling to comply with mandatory requirements. The use of the two pyramids proposed by Ian Ayres and John Braithwaite ensures the most suitable strategy for a particular regulated person and optimal achievement of regulatory purposes. The choice of a regulatory strategy depends on many factors, including at what stage the regulator intervenes in production - at the stage of organizing the activity or at the stage of product sales.

The interference in the production process by setting technology-based standards and monitoring their compliance is considered to be the least effective limiting technological development. The interference is effective at the last stage, when performance standards set requirements for the results, for example, for the content of harmful substances in emissions, dangerous chemicals or drugs in food products, etc. However, diesel-gates showed that manufacturers of powerful truck engines found a way to meet the requirements of performance standards, at the same time perverting the meaning of regulation. Interference at the stage of organizing the production process - management-based 
regulation - is the most promising regulatory strategy. The participation of managers and employees of regulated companies in achieving the social goals of regulation is necessary for it. According to this regulatory strategy it is necessary to plan and implement internal measures for identifying and eliminating threats, and training their employees. In some cases, companies are forced to create special internal services of compliance, production control and audit for this purpose. It is very important to evaluate the work and determine the efficiency of the planned actions, and the reason of the low efficiency in achieving the goals - poor quality of planning or inability to implement the planned actions in accordance with plan.

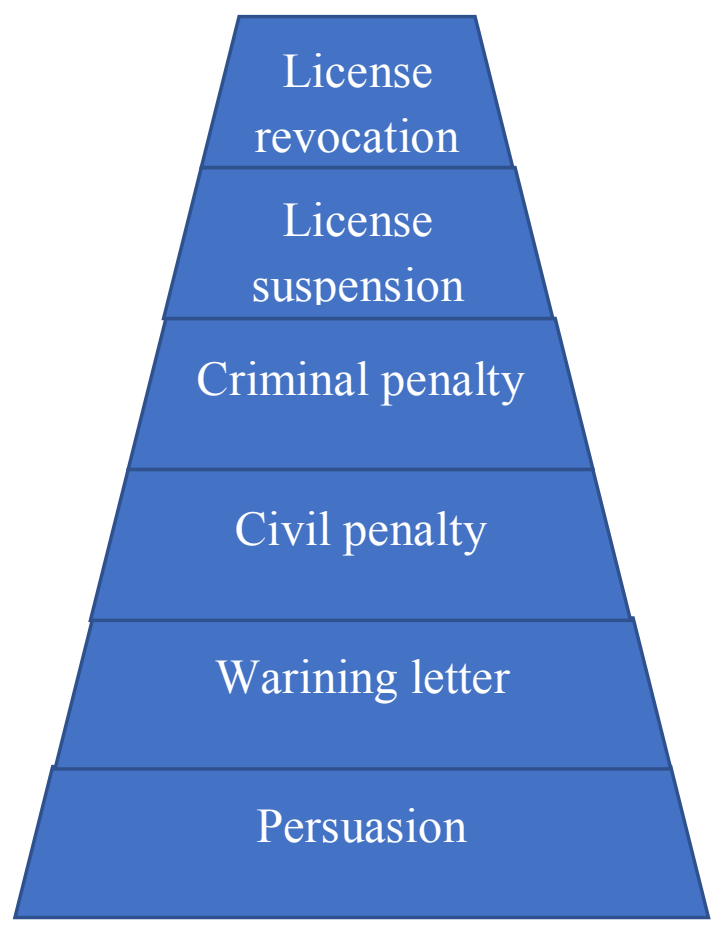

Fig.1. An enforcement pyramid by Ian Ayres and John Braithwaite, Responsive Regulation. Transcending the Deregulate Debate, Oxford University Press (1992):36.

But now leading foreign experts admit the importance to use not only legal means of regulation, but also other social norms (regulation is interpreted in this way), as well as cognitive means (John Brathwaite, Andrew Hoffman, John Scholz). We cannot define cognitive means yet. We mean the subconscious need to comply with the requirements, when a person even cannot think to do otherwise. In legal psychology, it is considered to be the highest level of legal awareness. According to empirical studies various informal sanctions (public criticism, discussions on social networks) have a stronger impact than formal legal fines, license revocations, etc. Inter alia informal sanctions, are not only more effective in achieving a long-term effect, but also they are much cheaper. The regulatory process should be flexible, it should involve managers and employees of regulated entities. It seems to us something unreal. Andrew Hoffman said: "The heresy of the 1960s became a dogma in the 1990s" We must assume that we will come to this.

\section{Protecting manufacturers interests}


Agricultural production involves an unusually wide range of participants of various industries, but almost all of them, except farms, play only a service staff role, providing the main manufacturing food products and raw materials for it. Despite this, they, as it turns out, may take a dominant position in relation to agricultural producers and dictate their conditions to them. Moreover, suppliers of resources and equipment (seeds, fertilizers, pesticides, machinery and equipment) as well as processing enterprises and retail chains can play this role. Unfair practices arise in markets with limited competition and insufficient information. In ideal situation, a manufacturer being at a disadvantage can go to another wholesale buyer and spread the information in the community. But in conditions when in the market power is concentrated in the hands of several large companies, the manufacturers are forced to conclude unprofitable deals for them. Small and medium-sized agricultural enterprises which cannot afford to leave the market captured by unscrupulous counterparties, according to the market laws are especially vulnerable. It is a market failure. Also it should be taken into consideration that small and medium-sized agricultural producers are severely limited in their ability to appeal to expensive and long legal protection. Farmers fear that appealing to court with a claim against a wholesale buyer may entail greater losses as a result of subsequent "repression".

Market failures are always considered to be the reason for government to involve market relations in the regulatory process. One of the widely used means of limiting unfair trade practices since the 70 s of the last century is the establishment of restrictions for retail chains (US-the Robinson-Patman Act). Similar laws have been adopted almost in all the European countries, not only the EU [5]. However, such regulation may be ineffective and even exacerbate regulatory problems in the food supply chain [6]. However, for example, restrictions on retail chains often are not effective, as well as measures to support farmers, which is resulted in the benefit for their suppliers and, again, retail chains. Since the beginning of 2000 the EU and US governments pay attention to the problems of effective and efficient regulation. At the same time, there is a rapid growth of scientific publications on regulation. In theory, five principles of smart regulation were formulated as in table 1.

Table 1. Principles of smart regulation by Neil Gunningham and Darrel Sinclair, Smart Regulation in P Drahos, Regulatory Theory: Foundations and Applications, 134-13 (2017).

\begin{tabular}{|l|}
\hline \multicolumn{1}{|c|}{ Principles of smart regulation [7]. } \\
\hline - preference for mixed regulatory tools to the use of a single tool avoiding at the same time the \\
"smorgasbord" problem» \\
\hline - gradual build-up of intervention \\
\hline - flexible regulation with feedback mechanisms to avoid regulatory errors \\
\hline - involvement of surrogate regulators, granting them the necessary rights \\
\hline - maximizing mutually beneficial opportunities \\
\hline
\end{tabular}

Perhaps, these principles were not fully taken into consideration in regulating unfair trade practices [6]. The notorious "smorgasbord" effect is still evident - some countries use a combination of public and private regulation, while others do not. At the same time, the EU proposed to use less interventionist measures - a pan-European voluntary initiative in the food sector - Supply Chain Initiative.

Then, due to the ongoing complaints on unfair trade practices escalating regulatory measures began in full conformity with the theory described by Ian Ayres and John Braithwaite (Responsive Regulation: Transcending the Deregulation Debate, 1992), moreover, according to Victoria Dashalova, this escalation was not coordinated, even within the EU and did not meet the criteria of subsidiarity and proportionality, that makes it possible to determine such regulation as counterproductive, when regulatory intervention reinforces the political problem, for the solution of which it was carried out [6]. 
Peter Grabosky called this phenomenon iatrogenesis and identified five types of regulatory intervention that can lead to similar consequences, as it regpresented in table 2 .

Table 2. Types of regulatory intervention that can lead to iatrogenesis.

\begin{tabular}{|l|}
\hline \multicolumn{1}{|c|}{ Types of regulatory intervention that can lead to iatrogenesis [8] } \\
\hline escalation \\
\hline displacement \\
\hline over-deterrence \\
\hline perverse incentives \\
\hline misunderstanding opportunity costs \\
\hline
\end{tabular}

Escalation takes place when the strengthening of measures aimed at eliminating the problem leads to its increase. At moving the problem transfers to another area or to another jurisdiction. Excessive deterrence can completely stop regulated activity. Perverse incentives are well-known regulatory traps, for example moral hazard. At last, an erroneous understanding of regulatory capabilities causes the situation when the elimination of regulated risk leads to unnecessarily high costs. Regulation of unfair trade practices is connected at least with 4 recent cases.

Sometimes displacement is connected with the departure of companies to offshore or simply to other jurisdictions in order to avoid the necessity to comply with costly mandatory rules. Also, it takes place when solving a problem in one policy area can make problems in another one. Thus, the Unfair Terms in Foodstuff Act, adopted by Slovakia in 2010 , led to the situation when retail chains began to avoid domestic producers. The next year that law was repealed. The law adopted in 2016 by Ireland for restricting the competition of goods coming from the UK is another example. Within the borders of the EU, this geographical movement was the result of the EU legislation non-interference and the national law-making disunity.

But improper regulation - both excessive and insufficient one - can lead to the escalation of the risks or problems which it was supposed to solve. Discounts on toxic waste encourage targeted waste production, since regulation mean providing subsidies for waste disposal, and preferential insurance leads to more risky behaviour of the insured person, because it removes personal responsibility for his/her actions [9].

Perverse incentives are connected with the situation when subsidizing farmers benefits both their suppliers inflating prices, and retail chains, undercutting prices, because farmer getting subsidies can afford to buy fertilizers, pesticides, seeds, fuel more expensive without harming the farm budget. In the same way, a farmer without harming to him/herself can sell products to a retail chain at a discount. As a result, benefits from subsidies go not to the manufacturer, but to the companies serving this manufacturer. Excessive deterrence leads to high costs of compliance with redundant requirements.

The EU legislation include provisions deviating from the antitrust requirements for agricultural producers, who are allowed to coordinate selling prices for milk, beef, olive oil and some other products. As an example of this agreement, however, aimed at ensuring the plant products safety, is the Marketing Agreement of manufacturers and Processors of LGMA products in California.

As for opportunity costs - mandatory requirements must be fulfilled, it needs proper law enforcement. Excessive enforcement is dangerous, as well as insufficient enforcement. Excessive regulation can completely stop the development of an enterprise or even an industry, or lead to turning on corrupt mechanisms. In accordance with empirical research we can also prove that strengthening of the requirements and responsibilities for their noncompliance is cause of the decrease in the efficiency of the field employees labour.

Thus, the applied regulatory strategies achieve their goal in supporting agricultural producers, allowing at the same time to inflate the prices of resources and reduce the 
purchase prices, ensuring the profit of companies serving farms. However, as a result all this support is carried out at the expense of agricultural products consumers and taxpayers.

\section{Food safety and environmental protection}

These areas are much more regulated. At the same time, we can see regulatory purposes conflict. Regulating relations methods in agriculture are extremely diverse, they can be aimed at achieving different goals (environmental protection, labour safety, product safety, support for farmers, antitrust regulation, etc.). Each direction of regulation, defined by a corresponding goal, is considered to be risk management, and different regulators may be responsible for it. For any of these goals it is necessary to achieve compromises. In addition, it is sometimes difficult to say which of the goals is more important. Thus, we need tools through which it is possible to reach compromises and make reasonable decisions.

The cost-benefit analysis is one of such tools. Margot J. Pollans argues that interagency cooperation or executive oversight are also used as tools [10]. In fact, there are much more such tools. For example, the Conservation Stewardship Program (USDA) is used as payments to farmers for implementing environmental practices. However, it is noted that such programs are not popular among farmers [11]. The program of labelling products as environmentally friendly, introduced in 1990, was promising. The Organic Foods Production Act, similar programs are now being introduced in other countries, too. However, their implementation shows ambiguous results $[12,13]$. We can make examples when the regulator actually imposes certification and labelling of products as environmentally friendly on manufacturers.

The environmental damage caused by agriculture as a result harms agriculture itself, making risks of soil erosion, water scarcity, and reduced resistance to pests and diseases [14]. But measures to counteract these consequences increase production costs such as crop rotation and reducing the use of pesticides. The report of the US Environmental Protection Agency notes that farmers are aging, their average age is 57 years old, and they are not going to give their business to their children and grandchildren, and this is reflected in their behaviour and interest in environmental protection [10].

The USDA has significant power to set standards for dairy products, meat, and poultry. Its structure includes the Food Safety Inspection Service, conducting inspections of farms and enterprises. Other agricultural products are regulated by the FDA [15]. In 2010 FDA got more power to ensure products safety and began to implement proactive regulation instead of the traditional surgical intervention after detecting a violation[16].

In accordance with the FSMA, adopted by the US Congress in 2011, the FDA's power was further expanded, its focus in food safety was shifted to prevention.

According to the law manufacturers and importers of food products must to make the risk analysis, develop the preventive HARPC control plans (improved HACCP, aimed at critical points) [17]. In addition, the law ordered the FDA to develop safety regulations for fresh food production, approved in 2015 and called as the FSMA.

The regulatory structure introduced by the USDA in the 1990s obliged regulated organizations to develop plans to reduce the risk to food safety and to implement production control. It is the "hazard analysis and critical control points" ("HACCP") system. This is an example of the transition from a command and control style of regulation to a promising "management-style regulation" [18]. Regulators all over the world, regardless of the areas of regulation, gradually abandon the command and control model of regulation based on deterrence with the threat of sanctions, and this is not accidental empirical studies show that in reality people behave more honestly [19]. 
As for the USDA, the implementation of the management-based regulation in the form of HACCP was supposed to be successful, since its activity is limited to the production only of meat, poultry and milk, and its inspectors always visited factories, but the regulation was unsuccessful because of the lack of trained specialists with knowledge about potential sources of microbial contamination. The plans of the enterprises turned out to be formal, and their revision needs long work. The USDA is not able to cover all the enterprises with inspections. Despite this, the tests showed a significant reduction of salmonella in meat in comparison with the basic data for a few years of the HACCP program implementation. And the CDC surveillance presented an overall reducing morbidity of tracked pathogens for five years. The program also affected environmental issues. During this time, we can see a decrease in the use of toxic pesticides. In this case, the principle of mutual learning and competition of regulated persons is used. Companies introduce new techniques it makes it possible to save on fertilizers, pesticides, and fines for pollution. Neighbours quickly adopt this experience and it becomes widespread.

The current Food Safety Act provides for the approval of the FDA performance standards, supporting the best manufacturing practices (GAP) and providing flexible regulation and the right for farmers to choose ways of reaching requirements set by these standards. However, the problem is complicated by conflicting requirements, high costs that farmers often are not able to do. For example, the requirement to sterilize the soil from pathogenic bacteria can lead to the microbial diversity loss and the decrease in soil productivity and the need to use more fertilizers [20].

The Marketing agreement Act of 1937 concluded by manufacturers and sellers is an interesting example of the regulation of leaf salad safety after the outbreak of intestinal disease in California in 2006

The LGMA Marketing agreement is an obligation of the parties to comply with the standards of the agreement to undergo the procedure of voluntary certification and obtain the right to use the conformity mark.

The California Department of Food and Agriculture (CDFA) has the power to make inspections from time to time for compliance with LGMA standards. The parties formed the Leafy Green Products Handler Advisory Board, managing the voluntary agreement between the firms and, on the basis of a contract with the CDFA, conducts an external audit of the leafy salad production [21]. It should be noted that the LGMA has almost reached the universal acceptance of its standards in California

Excessive enforcement may be due to the behavioural characteristics of the regulator's employees. The transition to management-style regulation makes their work more complicated, increases the qualification requirements. The field employee is not always able to understand the individual management decision of the farmer. In addition, farmers themselves often understand purposes of regulation and their role in it in different ways. Taking into consideration that product safety requirements are more strict, than environmental ones, that the FDA supervision is primarily focused on achieving the first goal, farmers are left to their own in prioritizing, it can be assumed that they will pay more attention to product safety.

Pollans notes that the Food Safety Act includes several trade-off management tools such as the cost-benefit analysis, the National Environmental Policy Act ("NEPA") compliance requirement, and the notice-and-comment in rulemaking procedure, but they do not work properly [10]. The co-regulation, the creation of non-state control organizations and the partial delegation of the inspection process to such external auditors is another promising tool [9]. However, in connection with this there is a problem of ensuring the proper supervision by the regulator. This problem can be solved before the rule-making procedure beginning, during the development and the adoption of standards, during their validity period. 
Before the rule-making process beginning, it is necessary to determine two important things on which the success (or failure) of regulation depends. These are how the legislator distributes the subjects of competence and powers of regulators, and how extensive the powers will be given to them.

There are risks connected with insufficient attention of the agency, ignoring related aspects and threats because of its own problems, and duplication of powers (tunnel vision).

It is possible to reduce the number of these risks by establishing mandatory consultations with other regulators and executive oversight by OIRA, by other means provided for by the Administrative Procedure Act, Regulatory Flexibility Act, etc.

Limited information on the basis of which the agency makes regulation is also the reason of risks in the rule-making process. Researchers note selective influence when the regulator pays more attention to one of the areas of its activity.

Pollans gives an example with Forest Service. Forest Service has to provide environment protection and regulate forest resources extraction, but it is accused of ignoring environmental problems [10].

The notice and comment process provided by the Administrative Procedure Act also plays an important role.

The Administrative Procedure Act makes it possible to take into consideration own opinions of farmers and all the interested groups of the population, whose interests may be affected by the developed solutions.

At last, after the final adoption of the rules, it is also possible to manage trade-offs. The important role in this process belongs to courts, but a regulator that remains committed to flexible regulation can do more by using performance standards, which only set goals, and the regulated persons can choose the most effective and convenient ways for achieving such goals.

Although new strategies appear in regulatory practice, the competition of regulatory objectives is still an unsolved problem, which is more and more compounded by the competition of regulatory agencies.

\section{Conclusion}

We in brief presented some challenges faced by regulators trying to ensure the development of agriculture, protect farmers, the environment, and the rights of consumers to food safety. Of course, because of the limited scope of the article, we could not investigate all the issues and means of regulation which coincide modern ideas about the forms, methods and limits of state interference into the private sector of the economy, such as agriculture. We did not investigate mandatory insurance, taxation, farm subsidy programs, the involvement of external auditors and industry associations, and we did not concern the analyses of the internal threats (lack of information, scarce resources, unclear goals, lack of mission understood and accepted by employees, low qualifications of employees, lagging behind in the development of technology, the economy digitalization, bureaucratic obstacles, regulatory capture and corruption).

According to our analyses regulatory agencies are forced to make decisions in difficult conditions of information lack, unpredictable changes, high probability of diseases spread, changes in supply and demand, political processes which the regulator cannot always influence, large territories where regulated persons operate. The regulation of agriculture is also extremely difficult for other reasons because simultaneously several regulatory agencies regulate this industry, and each of them strive to achieve several competing goals.

In these conditions, regulators can no longer act the old-fashioned way. This is expensive and inefficient. They are forced to develop new regulatory strategies, involve regulated persons in this activity, using management-based regulation technology, carry on 
trilateral negotiations, and take into consideration opinions of interested parties at the notes and comments stage in administrative procedures during developing rules and standards.

Thus, the post-ante analysis of regulation and the obtained results, the identification of problems and shortcomings, training based on this information, and the adjustment of regulatory models and strategies are very important components of the regulatory process. The regulator should be responsible for the results of this activity to politicians, society and regulated persons.

\section{References}

1. J.J. Czarnezki, E.K. Prescott, Food, Agriculture, and Environmental Law, 113, 113-29 (2013)

2. R.W. Adler, Agriculture and Water Quality: A Climate-Integrated Perspective, VT. L. REV, 37, 847, 850-57 (2013)

3. S. Zyryanov, A. Kalmykova, Economics and Business Administration, VIII, Special Issue 1, 84-91 (2020) doi: 10.35808 / ijeba / 507

4. C. Coglianese, Brookings Institution Press, 9 (2017)

5. L.Hou, S.Bargaining, SSRN Electronic Journal, 1-440 (2017)

6. V. Dashsalova, TILEC Discussion Paper: Tilburg University Press, 10 (2018)

7. N. Gunningham, D. Sinclair, Foundations and Applications, 134-13 (2017)

8. P. Grabosky, International Journal of the Sociology of Law, 23, 347-369 (1995)

9. C. Coglianese, H. Kunreuther, Brookings Institution Press, 238-250 (2017)

10. M. J. Pollans, Forest Law Review, 50, 401 (2015)

11. C.F. Sabel, W.H. Simon, Administrative State, GEO. L.J., 100, 53, 54-55 (2011)

12. T. K. Hass, Food \& Drug L.J., 68, 77, 87 (2013)

13. J. Guthman, Agrarian Dreams: The Paradox of Organic Farming in California (2014)

14. L.R. Brown, Full Planet, Empty Plates: The New Geopolitics of Food Scarcity, 83-85 (2012).

15. R.Johnson, The Federal Food Safety System: A Primer, 2-4 (2014)

16. C. F. Sabel, W.H. Simon, MICH. L. REV, 110, 1265, 1280 (2012)

17. N. Fortin, Duke Environmental Law \& Policy Forum, XXV, 313-337 (2015)

18. C. Coglianese, S. Starobin, Public Law and Legal Theory Research Paper Series, 20-41 (2020)

19. T. Herzfeld, R. Jongeneel, Land Use Policy, 29, 250-260 (2012)

20. C. Kremen, A. Miles, Ecology \& Soc'y Art, 17, 40-43 (2012).

21. T. D. Lytton, Technical Standards in Health \& Safety Regulation: Risk Regimes, the New Administrative Law, and Food Safety Governance, Cambridge Handbook Of Technical Standardization Law, 2, (2019) 